\title{
EXPOSURE BASED THERAPY PADA FOBIA KETINGGIAN
}

\author{
Fatimah* Yulianti E** \\ * Dokter Umum, Peserta PPDS I Prodi Psikiatri Departemen/SMF Ilmu Kedokteran Jiwa FK UNAIR/RSUD dr. Soetomo Surabaya \\ **Dokter Spesialis Kedokteran Jiwa/Psikiater, Psikiater Konsultan, Staf Pengajar Departemen/SMF Ilmu Kedokteran Jiwa FK UNAIR/RSUD dr. Soetomo \\ Surabaya
}

\begin{abstract}
ABSTRAK
Acrophobia adalah ketakutan terhadap ketinggian yang berlebihan atau irasional yang digolongkan sebagai fobia spesifik. Fobia spesifik merupakan salah satu bentuk umum dari gangguan kecemasan yang dapat menimbulkan disabilitas pada penderitanya karena perilaku menghindar dari obyek yang ditakuti dapat menimbulkan hendaya yang bermakna pada hubungan sosial dan pekerjaan. Acrophobia sering dihubungkan dengan penghindaran bermacam-macam situasi yang berhubungan dengan ketinggian misalnya, perjalanan dengan menggunakan pesawat terbang, menaiki tangga, menaiki lift, jembatan dan menghindari bekerja di gedung yang berlantai tinggi. Terapi berbasis bukti yang dapat dipergunakan meliputi farmakoterapi, terapi paparan (exposure based therapy) dan restrukturisasi kognitif. Exposure based therapy merupakan salah satu terapi pilihan yang terbukti efektif selama beberapa dekade untuk menurunkan kecemasan, distress dan hendaya fungsional atau okupasional yang diakibatkan oleh penghindaran obyek atau situasi fobia. Pendekatan yang digunakan dalam exposure therapy antara lain in vivo exposure (traditional exposure dan virtual reality exposure, systematic desensitization, imaginal exposure, dan flooding therapy.
\end{abstract}

Kata Kunci: acrophobia, fobia spesifik, exposure based therapy

Corresponding author: Fatimah, dr.

Dep/SMF Kedokteran Jiwa FK UNAIR/RSUD Dr.SoetomoSurabaya

email: fatimahdr82@gmail.com 


\section{PENDAHULUAN}

Fobia merupakan suatu kondisi dimana terdapat ketakutan irasional terhadap suatu benda meskipun tidak ada bahaya nyata yang mengancam. Fobia ketinggian atau yang dikenal dengan acrophobia merupakan salah satu jenis dari fobia spesifik yang menurut Diagnostic and Statistical Manual of Mental Health Disorders Edisi V (DSM-V), didefinisikan sebagai ketakutan terhadap ketinggian yang ekstrem (Coelho et al., 2009; Bouchard et al., 2012).

Prevalensi seumur hidup dari fobia spesifik di Amerika Serikat, berkisar sebesar 15.6\%, sedangkan acrophobia sebesar 3.1-4.4\% yang pada umumnya lebih banyak terjadi pada wanita daripada pria (Huppert, Grill and Brandt, 2017; Rudaz et al., 2017).

Fobia spesifik merupakan salah satu bentuk umum dari gangguan kecemasan yang dapat menimbulkan disabilitas pada penderitanya karena perilaku menghindar dari obyek yang ditakuti dapat menimbulkan hendaya yang bermakna pada hubungan sosial dan pekerjaan (Witthauer et al., 2016).

Berbagai kondisi yang sering dialami seseorang yang mengalami acrophobia adalah penghindaran bermacammacam situasi yang berhubungan dengan ketinggian misalnya, perjalanan dengan menggunakan pesawat terbang, menaiki tangga, menaiki lift, jembatan, menghindari bekerja di gedung yang berlantai tinggi dan balkon apartemen (Coelho et al., 2009).

Modalitas terapi berbasis bukti yang dapat digunakan pada acrophobia yaitu dengan terapi farmakologi dan nonfarmakologi. Obat-obatan golongan serotonin selective reuptake inhibitor, benzodiazepine dan $d$-cycloserine dapat dipergunakan pada terapi farmakologi. Exposure based therapy dan terapi kognitif atau kombinasi keduanya merupakan pengobatan non-farmakologi yang sering dipergunakan (Rodrigues et al., 2014).

Exposure based therapy merupakan salah satu terapi pilihan yang terbukti efektif selama beberapa dekade yang mulai digunakan sejak tahun 1950. Pada exposure therapy, pasien dipaparkan secara langsung kepada situasi yang ditakuti dengan cara yang sistematis dan terstruktur sementara itu dilakukan pencegahan timbulnya perilaku atau pikiran menghindari situasi fobia (Kaplan JS and Tolin DF, 2011; Wolitzky-Taylor et al., 2008; Craske et al., 2014). Tujuan dari terapi adalah untuk menurunkan rasa takut, perilaku menghindar, distress dan hendaya fungsional yang dialami oleh penderita akibat perilaku menghindari obyek yang ditakutinya (Hofmann, 2009; Bouchard et al., 2012).

\section{PEMBAHASAN}

Fobia ketinggian atau yang dikenal dengan acrophobia adalah ketakutan terhadap ketinggian yang ekstrem atau irational. Acrophobia merupakan salah satu jenis dari fobia spesifik yang menurut Diagnostic and Statistical Manu- al of Mental Health Disorders Edisi V (DSM-V) digolongkan sebagai tipe lingkungan alami (Leboucher et al., 2015; Misiewicz et al., 2016).

Faktor yang berkontribusi terhadap timbulnya acrophobia yaitu jalur non-associative. Beberapa peneliti mengusulkan faktor herediter atau jalur non-associative sebagai faktor yang berkontribusi terhadap perkembangan fobia ketinggian. Hal ini disebabkan karena beberapa individu yang memiliki fobia ini tidak dapat menjelaskan pengalaman yang bermakna terkait fobia sebagai faktor etiologi utama. Penelitian yang dilakukan oleh Menzies dan Clarke (1993) dengan membandingkan 2 grup induvidu yang mempunyai acrophobia dan individu normal (kontrol), menunjukkan hasil pada grup acrophobia sebanyak 21 orang partisipan menderita acrophobia karena jalur non-associative, sementara pada grup kontrol didapatkan individu yang memiliki pengalaman traumatis terkait ketinggian namun tidak mengalami acrophobia (Coelho et al., 2009).

Peran dari teori kognitif juga berkontribusi dalam acrophobia. Menzies dan Clarck (1995) mengemukakan bahwa seseorang yang menderita acrophobia mengalami bias interpretasi yaitu melebih-lebihkan bahaya atau meragukan kemampuan mereka menghadapi kecemasan terkait situasi ketinggian (Steinman and Teachman, 2012).

Peranan sistem visual dan vestibular dalam acrophobia dapat dijelaskan sebagai konflik antara indera penglihatan, keseimbangan dan somatosensori. Hal tersebut terjadi akibat timbulnya diskrepansi antara reseptor vestibular dan somatosensori ketika terjadi pergerakan tubuh (kepala bergerak $2 \mathrm{~cm}$ ke arah samping) yang tidak terdeteksi oleh sistem visual karena jarak yang lebar dari obyek terdekat yang dilihat (Coelho et al., 2009, Coelho C.M and Wallis G., 2010).

Pedoman diagnostik menurut ICD-10 dan PPDGJ-III menggolongkan acrophobia ke dalam fobia khas (terisolasi) dengan kriteria diagnostik sebagai berikut :

Semua kriteria di bawah ini harus dipenuhi untuk diagnosis pasti :

gejala psikologis, perilaku atau otonomik yang timbul harus merupakan manifestasi primer dari anxietasnya dan bukan sekunder dari gejala-gejala lain seperti misalnya waham atau pikiran obsesif;

kecemasan harus terbatas pada adanya objek atau situasi fobik tertentu (highly spesific situations); dan

situasi fobik tersebut sedapat mungkin dihindarinya.

Pada fobia khas ini umumnya tidak ada gejala psikiatrik lain, seperti halnya agorafobia dan fobia sosial.

(Pedoman Penggolongan dan Diagnosis Gangguan Jiwa di Indonesia (PPDGJ) III)

Penatalaksanaan awal pada acrophobia meliputi assessment awal, self report measure dan behavioural assessment. Assessment awal untuk acrophobia meliputi pengambilan data tentang riwayat psikiatrik dan pemeriksaan status mental. Evaluasi menyeluruh dapat dilakukan seperti wawancara terstruktur, self report measure, dan penilaian perilaku (Kanwal, Rajender and Grover, 2008). Beberapa kuesioner yang dapat dipergunakan yaitu Acrophobia Questionnaire and Subjective Units of Disturbance Scale (SUDS) yang telah teruji validitas dan sensitifitasnya (Coelho C.M and Wallis G., 2010). Behavioral Avoidance 
Test (BAT) dapat dilakukan untuk penilaian perilaku yaitu dengan meminta pasien untuk memasuki situasi yang ditakti dan mengukur responnya. Hal tersebut dapat dilakukan secara langsung maupun dengan cara membayangkan (imaginary). Pasien diminta untuk membuat skala verbal dari rasa takut yang dirasakan saat BAT dengan menggunakan Subjective Units of Disturbance Scale (SUDS) dengan skala 0 hingga 100. Skala 100 menunjukkan rasa takut terburuk atau distres terberat yang terbayang sedangkan skala 0 menunjukkan tidak ada rasa takut sama sekali (Coelho et al., 2008; Ollendick, Raishevich and Iii, 2012).

Penatalaksaan lanjutan pada acrophobia dapat merupakan kombinasi dari Exposure Based Therapy, terapi kognitif dan farmakoerapi. Terapi kognitif bertujuan merubah belief, ekspektasi dan prediksi seseorang terhadap kemungkinan atau konsekuensi yang dapat timbul akibat berhadapan dengan situasi fobianya untuk mengurangi kecemasan dan perilaku menghindar. Terapi kognitif bila dipergunakan bersama dengan exposure therapy merupakan terapi yang potensial. Beberapa penelitian menyebutkan pada penggunaan tunggal tanpa kombinasi, kurang efektif bila dibandingkan dengan exposure therapy saja (Bouchard et al., 2012).

Penelitian menyebutkan pemberian farmakoterapi seperti obat-obatan anxiolytic sebaiknya tidak dilakukan karena tidak terbukti efektifitasnya. Pemberian benzodiazepin bersamaan dengan dilakukannya terapi exposure akan mengaburkan gejala dan dapat menimbulkan kekambuhan saat pengobatan dihentikan (Choy et al, 2010).

Efektivitas penggunaan obat-obatan golongan glukokortikoid seperti D-cycloserine pada beberapa penelitian terbaru yang dilakukan menunjukkan hasil yang baik dengan menargetkan kepada perbaikan proses belajar sela- ma terapi exposure. D-cycloserine (DCS) merupakan obat parsial agonis dari $N$-methyl-D-aspartat (NMDA) reseptor glutamatergik (Choy et al, 2010).

Exposure based therapy adalah tehnik yang dipergunakan dengan memaparkan individu secara sengaja terhadap obyek atau situasi yang ditakuti namun tidak membahayakan bagi individu tersebut untuk memunculkan perilaku atau respon emosional yang tidak diharapkan (Kaplan JS and Tolin DF, 2011; Bouchard et al., 2012; Craske et al., 2014; Rudaz et al., 2017). Tehnik pendekatan yang digunakan dalam exposure therapy antara lain sebagai beri- kut :

a. In vivo exposure (traditional exposure dan virtual reality exposure)

b. Systematic desensitization

c. Imaginal exposure

d. Flooding therapy

(Wolitzky-Taylor et al., 2008)

\section{Imaginary exposure}

Pada imaginary exposure pasien diminta untuk menutup kedua mata dan membayangkan sejelas-jelasnya ten- tang obyek atau situasi yang ditakutinya. Imaginary exposure dapat dipergunakan sebagai terapi awal sebelum dilakukan in vivo exposure. Setelah dilakukan imaginary exposure dan derajat kecemasan akibat antisipasi berkurang, pasien dapat menjalani terapi in vivo dimana pasien akan berhadapan secara langsung (Kaplan JS and Tolin DF, 2011; Sadock BJ, Sadock VA, Ruiz P 2015).

Imaginary exposure dapat memberikan waktu kepada pasien utuk memproses rasa takut yang dirasakan yang biasanya dihindari baik melalui perilaku (menghindari kontak) atau secara kognitif (menghindari memikirkan tentang konsekuensi atau perasaan bila berada dalam situasi ketinggian). Hal tersebut dapat mengurangi respon emosi sehingga keyakinan bahwa kemungkinan kejadian yang ditakutkan akan muncul dapat menurun, mengajarkan kepada pasien tentang beda kenyataan dan pemikirannya sendiri dan bahwa akibat yang dapat terjadi lebih ringan daripada yang dibayangkannya. Pada individu yang memiliki riwayat trauma terkait dengan fobianya, maka tehnik ini dapat mengajarkan pasien untuk membedakan antara memori traumatis yang memang berbahaya dengan kenyataan saat ini, yang meskipun membuat distress tapi tidak berbahaya (Kaplan JS and Tolin DF, 2011; Levinson C, Rapp E and Riley E, 2013; Sadock BJ, Sadock VA, Ruiz P 2015).

\section{Systematic desensitization}

Systematic desensitization merupakan terapi perilaku yang dikembangkan oleh Wolpe di tahun 1958 yang berdasar pada prinsip classical conditioning. Tujuan terapi ini adalah untuk mengurangi respon emosi dari fobia dengan menghubungkan hal yang ditakutkan dengan sesuatu yang menenangkan atau menyenangkan dan dilakukan secara gradual (bertahap). Tehnik ini mengajarkan pasien merelaksasikan otot-otot volunter selama pemaparan dengan situasi fobianya baik secara imaginary atau in vivo (Mcleod S, 2015; Wolitzky-Taylor et al., 2008).

Terdapat tiga fase dalam tehnik systematic desensitization yaitu :

Pasien diajarkan tehnik relaksasi otot progresif dimana akan menghasilkan suatu respon inhibisi yang tidak kompatibel dengan stimulus (resiprokal inhibisi). Pada kasus fobia rasa takut melibatkan ketegangan dan ketegangan sendiri tidak kompatibel dengan relaksasi.

Pasien diminta untuk membuat hirarki derajat rasa takut yang berkaitan dengan fobia ketinggiannya yang dimulai dari stimulus yang dapat memunculkan rasa takut terendah hingga tertinggi.

Pasien memulai terapi desensitisasinya dengan tehnik im- aginary atau in vivo secara bertahap sesuai dengan hirarki rasa takut yang telah dibuatnya sambil melakukan tehnik relaksasi.

(Groves G, 2010; Craske et al., 2014)

\section{Traditional exposure}

Sebuah penelitian dilakukan oleh Coelho et al (2008) pada 5 orang individu dengan fobia ketinggian (tangga dan teras 
balkon) menggunakan tehnik traditional exposure yang dilakukan oleh psikolog klinis. Penelitian dilakukan sebanyak 3 sesi dengan durasi 50 menit tiap sesi satu kali per minggu selama 3 minggu.

Sebelum sesi terapi dimulai dilakukan behavioural avoidance test (BAT) dengan meminta partisipan menaiki 40 anak tangga secara bertahap. Subyek menaiki 5 anak tangga dan berhenti selama 10 detik dan melihat ke arah sekeliling, selama jeda waktu ini dilakukan Subjective Units of Disturbance Scale (SUDS). Prosedur dilanjutkan hingga partisipan tidak mampu menaiki anak tangga lagi atau sudah tiba di ujung anak tangga. Selama sesi berlangsung, terapis memberi penguatan kepada partisipan bahwa ia mampu mencapai balkon, naik ke berbagai lantai dan menunjukkan penurunan nilai SUDS. Selama sesi partisipan tetap diminta untuk melihat ke arah lantai, sekeliling dan bertahan selama mungkin hingga kecemasannya berkurang. Ketika kecemasan sudah berkurang, terapis meminta partisipan melanjutkan ke lantai yang lebih tinggi atau meraih tepi balkon teras. Sesi berikutnya dimulai dari tempat sesi sebelumnya berakhir (Cottraux, 2002; Coelho et al., 2008, 2009; Coelho C.M and Wallis G., 2010)

\section{Virtual reality exposure}

Virtual reality sekarang merupakan teknologi yang menjadi tren di dunia. Virtual reality adalah dunia virtual yang mendekati gambaran dunia nyata. Virtual reality exposure therapy (VRET) adalah salah satu bentuk in vivo exposure therapy yang menurut berbagai penelitian memiliki efektifitas yang tinggi sebagai terapi untuk acrophobia dan menghasilkan outcome yang lebih baik dibandingkan dengan imaginary exposure (Emmelkamp, 2015; Suyanto et al., 2017)

VRET menggunakan simulasi berbasis komputer dimana individu terhubung dengan lingkungan virtual yang berjalan secara alami melalui pergerakan kepala atau tubuh melalui head mount. Pada saat seseorang terhubung dengan dunia virtual, dapat dipaparkan dengan stimulus yang ditakuti yang menyerupai dunia nyata (Parsons and Rizzo, 2008).

Lingkungan serupa di dunia nyata diciptakan di dalam dunia virtual yang menggambarkan situasi yang dapat memicu kecemasan akibat fobia ketinggian misalnya gedung perkantoran yang memiliki balkon di lantai yang tinggi, jembatan gantung bahkan simulasi penerbangan (Suyanto et al., 2017).

Penelitian yang dilakukan oleh Coelho et al (2008) terhadap 10 orang partisipan acrophobia menggunakan tehnik VRET dibandingkan dengan kelompok yang menggunakan tehnik traditional in vivo exposure didapatkan hasil efektifitas yang sama antara kedua kelompok dengan waktu sesi VRET yang lebih pendek yaitu 22 menit dibandingkan tehnik tradisional 50 menit (Coelho et al., 2008).

Sebuah penelitian meta-analisis yang dilakukan oleh Powers dan Emmelkamp (2008) menunjukkan bahwa VRET terbukti secara bermakna lebih efektif dibandingkan terapi gold standart fobia spesifik yaitu in vivo exposure (Coelho et al., 2009).
VERT memiliki keuntungan bila dibandingkan dengan tehnik traditional exposure yaitu antara lain :

penghindaran rasa malu yang mungkin timbul di area publik

lebih menjaga kerahasiaan terapi

lebih menarik penderita untuk mau mengikuti terapi

situasi yang lebih mudah dikontrol oleh terapis

(Coelho et al., 2008)

\section{Flooding therapy}

Pada flooding therapy pasien diminta untuk memasuki situasi fobia paling buruk yang mungkin terjadi dan mengalami rasa takut dalam derajat yang maksimum selama satu jam sampai pasien tidak mampu lagi mengalami rasa takut tersebut (Zoellner et al, 2008).

Tehnik ini awalnya dilakukan dengan cara imaginary lalu dilanjutkan dengan in vivo exposure (paparan langsung). Misalnya pada pasien yang mengalami fobia ketinggiaan terkait lift, pasien dapat diminta untuk membayangkan dirinya terjebak di dalam lift selama berjam-jam tanpa ada alat komunikasi dengan orang lain. Terapis dapat menambahkan komentar selama pasien menjalani terapi untuk memunculkan kecemasan yang maksimal selama mungkin. Derajat kecemasan fobik dinilai berdasarkan perilaku pasien (misalnya mimik wajah dan jari-jari tangan yang mengepal), laporan subyektif dari pasien dan pengukuran denyut jantung selama sesi terapi (Zoellner et al, 2008).

Setelah kecemasan tampak berkurang, maka variasi adegan baru mulai diberikan. Pasien juga dapat diminta melakukan sesi terapinya di rumah. Setelah beberapa sesi pasien dapat kehilangan rasa kecemasan terhadap adegan yang dibayangkan dan mulai dapat dipaparkan pada situasi di kehidupan nyata (Zoellner et al, 2008; Levinson C, Rapp E, Riley E, 2013).

Sebelum terapi dimulai, pasien diinformasikan bahwa apa yang akan dialami pada awalnya tidak nyaman dan mereka dapat menghentikan sesi terapi sewaktu-waktu. Namun agar terapi dapat bekerja secara efektif, diperlukan untuk pasien mengalami rasa takut selama mungkin saat sesi terapinya dan tidak ada obat-obatan yang diberikan selama terapi dijalankan (Zoellner et al, 2008)

\section{RINGKASAN}

Fobia ketinggian atau acrophobia yaitu ketakutan terhadap ketinggian yang ekstrem merupakan salah satu jenis dari fobia spesifik tipe lingkungan alami. Acrophobia sering menimbulkan penghindaran berbagai macam situasi yang berhubungan dengan ketinggian misalnya, perjalanan dengan menggunakan pesawat terbang, menaiki tangga, menaiki lift, jembatan, menghindari bekerja di gedung yang berlantai tinggi dan balkon apartemen. Acrophobia dapat menimbulkan disabilitas pada penderitanya karena perilaku menghindar dari obyek yang ditakuti dapat menimbulkan hendaya yang bermakna pada hubungan sosial dan pekerjaan. 
Exposure based therapy merupakan gold standart untuk terapi pada acrophobia. Terapi in vivo exposure memiliki efikasi yang lebih besar bila dibandingkan dengan imaginary exposure. Virtual reality exposure therapy (VRET) memiliki efektifitas yang sama dengan traditional in vivo exposure therapy dengan durasi yang lebih pendek dalam mencapai outcome yang sama. Pemberian psikofarmaka misalnya anxiolytic bersamaan dengan dilakukannya terapi exposure tidak dianjurkan karena akan mengaburkan gejala dan dapat menimbulkan kekambuhan saat pengobatan dihentikan.

\section{DAFTAR PUSTAKA}

Bouchard, S. Robillard, G. Larouche, G. Loranger, G. (2012) 'Description of a Treatment Manual for in virtuo Exposure with Specific Phobia'. Virtual Reality in Psychological, Medical and Pedagogical Applications. $10.5772 / 46417$.

Choi, D.C. Rothbaum, B.O. Gerardi, M. Ressler, K.J. Stein,M.B. Steckler,T. (2010) 'Behavioural Neurobiology and It's Treatment',. Springer, Berlin. pp.239.https:// sites.oxy.edu/clint/physio/article/

BehavioralNeurobiologyofAnxietyanditsTreat-

ment_book.pdf

Coelho, C. M. Silva, C.F. Tichon, J. Wallis, G. (2008) 'Contrasting the Effectiveness and Efficiency of Virtual Reality and Real Environments in the Treatment of Acrophobia', 6(2), PsychNology Journal, 2008, 6(2), 203-216. pp.

203-216.https://

pdfs.semanticscholar.org/7e59/337efa86e951974c1578b50

711908b193962.pdf

Coelho, C. M. Waters, A.M. Hine, T.J, Wallis, G. (2009)

'The use of virtual reality in acrophobia research and treatment', 23, J Anxiety Disord. 2009 Jun;23(5). pp. 563-574. doi: 10.1016/j.janxdis.2009.01.014.

Coelho, C.M, Wallis G (2010) 'Deconstructing Acrophobia : Physiological and Psychological Precursors to Developing Fear of Height. Depression and Anxiety. 27 (9).pp. 864 - 870. 10.1002/da.20698.

Cottraux, J. (2002) 'Nonpharmacological treatments for anxiety disorders', Dialogues in Clinical Neuroscience, 4 (3), pp. 305-319.https://www.ncbi.nlm.nih.gov/pmc/ articles/PMC3181686/

Craske, M. G. Treanor,M. Conway, C. Zbozinek T, Vervliet, B. (2014) 'Maximizing exposure therapy: an inhibitory learning approach.', Behaviour research and therapy. NIH Public Access, 58, pp. 10-23. doi: 10.1016/ j.brat.2014.04.006.

Departemen Kesehatan Republik Indonesia, 1993, Pedoman Penggolongan dan Diagnosis Gangguan Jiwa di Indonesia (PPDGJ) III. Cet. Pertama. Jakarta: Departemen Kesehatan.

Emmelkamp, K. (2015) Virtual Reality Treatment in Acrophobia : A Comparison with Exposure in Vivo Virtual reality treatment versus exposure in vivo : a comparative evaluation in acrophobia. Cyber Psychology \& Behavior, 4(3). doi: 10.1089/109493101300210222.
Groves, G. (2012), 'Psychotherapy Guidebook Systematic Desensitization', United States of America. e-Book 2016 International Psychotherapy Institute. pp 1-10.

Hofmann, S. G. (2009) 'Cognitive processes during fear acquisition and extinction in animals and humans: Implications for exposure therapy of anxiety disorders'. Clinical Psychology Review 03 May 2007, 28(2):199-210. DOI: 10.1016/j.cpr.2007.04.009

Huppert, D., Grill, E. and Brandt, T. (2017) 'A new questionnaire for estimating the severity of visual height intolerance and acrophobia by a metric interval scale', Frontiers in Neurology, 8(JUN), pp. 1-8. doi: 10.3389/ fneur.2017.00211.

Kanwal, K., Rajender, G. and Grover, N. (2008) 'Management of Specific Phobias', Journal of Mental Health \& Human Behavior, 2008, 13(2). pp. 17-26. https:// pdfs.semanticscholar.org/

d795/4542f9663c098feaf15beaaf76b41d3919a4.pdf

Kaplan, J.S., Tolin, D.F., (2011), ' Exposure Therapy for Anxiety Disorders', http://www.psychiatrictimes.com/ anxiety/exposure-therapy-anxiety-disorders.Diakses tanggal 10 Januari 2018.

Leboucher, P. Levy, F, Rautureau G, Jouvent, R. (2015) 'Evirtual reality exposure therapy in acrophobia: A pilot study E-virtual reality exposure therapy in acrophobia : A pilot study', (August).Journal of Telemedicine and Telecare,22,pp.1-6, 2015. doi: 10.1177/1357633X15598243.

Levinson C, Rapp E, R. E. (2013) 'Addressing the Fear of Fat: Extending Imaginal Exposure Therapy for Anxiety Disorders to Anorexia Nervosa', 31(9), HHS Public Acscess. pp. 1713-1723. doi: 10.1007/s40519-014-0115-6

McLeod, S. (2015), ' Systematic Desensitization',https:// www.simplypsychology.

org/Systematic-Desensitisation.html.Diakses tanggal 2 Januari 2018.

Misiewicz, Z. Hiekkalinna, T. Paunio, T. Varilo, T. Terwilliger, DJ.D, Partonen, T. Hovatta, I. (2016) 'A genomewide screen for acrophobia susceptibility loci in a Finnish isolate', Scientific Reports. Nature Publishing Group, 6, pp. 1-9. doi: 10.1038/srep39345.

Ollendick, T. H., Raishevich, N. and Iii, T. E. D. (2012) 'NIH Public Access', 41(1), pp. 133-141. doi: 10.1016/ j.beth.2009.02.002.Specific.

Parsons, T. D. and Rizzo, A. A. (2008) 'Affective outcomes of virtual reality exposure therapy for anxiety and specific phobias: A meta-analysis', APA PsycNET, 39, pp. 250-261. doi: 10.1016/j.jbtep.2007.07.007.

Rodrigues, H. Figuera, I. Lopes, A. Goncalves, R. Mendlowicz, M.V. Coutinho, E.S.F. Ventura, P. (2014) 'Does dcycloserine enhance exposure therapy for anxiety disorders in humans? A meta-analysis', PLoS ONE, 9(7), pp. 1-12. doi: 10.1371/journal.pone.0093519.

Rudaz, M. Ledermann, T. Margraf, J, Becker, E.S, Craske. M.G. (2017). 'The moderating role of avoidance behavior 
on anxiety over time: Is there a difference between social anxiety disorder and specific phobia?',PLoS ONE.12(7). pp. 1-14.doi: 10.1371/journal.pone.0180298.

Saddock, B.J, Saddock, B.A, Ruiz P (2015) Synopsis of Psychiatry : Behavioural Sciences and Clinical Psychiatry 11th ed, Philadephia : Lippincont Williams \& Wilkins.pp.866-871.

Steinman, S. A. and Teachman, B. A. (2012). Cognitive Processing and Acrophobia: Validating the Heights Interpretation Questionnaire. 'NIH Public Access', 25(7), pp. 896-902. doi: 10.1016/j.janxdis.2011.05.001.Cognitive.

Suyanto, E. M. Angkasa, D. Turaga, H. Sutoyo, R. (2017) 'Overcome Acrophobia with the Help of Virtual Reality and Kinect Technology ScienceDirect ScienceDirect Overcome Acrophobia with the Help of Virtual Reality Overcome Acrophobia with the Help of Virtual Reality and Kinect Technology and Kinect Technology', Procedia Computer Science. Elsevier B.V., 116, pp. 476-483. doi: 10.1016/j.procs.2017.10.062.

Witthauer, C. Ajadic-Gross, V. Meyer,H.M. Vollenwelder, P. Waeber, G. Preisig, M, Lieb.R. (2016) 'Associations of specific phobia and its subtypes with physical diseases : an adult community study', BMC Psychiatry. BMC Psychiatry,16:155, pp. 1-10. doi: 10.1186/s12888-016-0863-0.

Zoellner,L.A. Abramowitz,J.S. Moore,S.A. Slagle. D.M, O’Donohue, W.T. Fisher, J.E.(2008) 'Cognitive Behaviour Therapy Appying Empirically Supported Tehniques in Your Practices', John Wiley \&Sons, Inc, New Jersey. Second edition. pp.202-206. 